\title{
A spectrophotometric and NMR study on the formation of an inclusion complex between dopamine and a sulfonated cyclodextrin host
}

\author{
Gillian M. Hendy*, Carmel B. Breslin \\ Department of Chemistry, National University of Ireland Maynooth, Maynooth, Co. Kildare, Ireland
}

\section{A R T I C L E I N F O}

\section{Article history:}

Received 2 May 2011

Received in revised form 20 July 2011

Accepted 25 July 2011

Available online 9 August 2011

Keywords:

Inclusion complex

$\beta$-cyclodextrin

Dopamine

\begin{abstract}
A B S T R A C T
The formation of an inclusion complex between the sulfonated $\beta$-cyclodextrin ( $S \beta-C D$ ) with dopamine (DA) was confirmed using UV-vis measurements and NMR methods. It was also established that a 1:1 complex was formed between the $S \beta-C D$ and the DA, where the inclusion occurred predominantly through the aromatic ring of the DA and the hydrophobic $C D$ cavity. The results also suggest that a change in the anion, of supporting electrolyte, had an influence on the DA-S $\beta-C D$ complexation while no change was observed for the cation.
\end{abstract}

() 2011 Elsevier B.V. All rights reserved.

\section{Introduction}

Cyclodextrins (CD) are macrocyclic oligosaccharides composed of $\alpha$-D-glucopyranoside units. The three common members are $\alpha-, \beta$ - and $\gamma-C D$, which have 6,7 , and 8 repeating glucopyranoside units, respectively. These units are orientated in a cyclic manner giving the typical conical or truncated cone structure with a relatively hydrophobic interior and a hydrophilic exterior [1]. This structure gives cyclodextrins their unique ability to form host-guest inclusion complexes with a wide range of suitably sized guest molecules [2-8]. In these complexes, the guest molecule is held within the cavity of the cyclodextrin host system. Penetration of the guest molecule into the cavity may be complete or, alternatively, only part of the guest molecule may fit within the cavity.

Formation of the host-guest complex can be easily monitored using techniques such as UV-visible spectroscopy (UV-vis), nuclear magnetic resonance (NMR), fluorescence spectroscopy, IR spectroscopy, electrochemical approaches and solubility measurements [9-11], as the physiochemical properties of the guest molecule caged within the host cavity is very different to that of the free guest.

Recently, charged cyclodextrins have received a lot of attention as chiral selectors in capillary electrophoresis [12-14]. It has been suggested that the anionic CDs provide maximum separation by migrating in opposite directions to the analyte [15]. In particular, sulfated and highly sulfated $\beta-\mathrm{CD}$ s have been used with some

\footnotetext{
* Corresponding author. Present address: Koch Institute at MIT, 76-661, 77 Massachusetts Avenue, Cambridge, MA 02139, United States. Tel.: +1 617253 3638; fax: +16172588827 .

E-mail addresses: ghendy@mit.edu (G.M. Hendy), carmel.breslin@nuim.ie (C.B. Breslin).
}

success [12-15]. A number of studies have been carried out on the characterization of these CDs. For example, Amini et al. [16] reported that sulfation occurs predominantly at the C-2 and C-6 positions, while, Chen et al. [17] confirmed nearly complete sulfation at the C -6 position of the primary hydroxyl groups and partial sulfation at the C-2 secondary hydroxyl groups. However, no substitution, or sulfation, occurred at the C-3 positions.

Although sulfonated cyclodextrins have been used in capillary electrophoresis, there have been very few studies devoted to the formation of inclusion complexes between sulfonated $\beta-C D$ and guest molecules, or indeed between guest molecules and any anionic $\beta-C D$. One example is a study by Rajewski et al. $[18,19]$ who investigated the role of charge by comparing the binding of neutral and charged cyclodextrins with neutral and charged guests. They found that the negatively charged sulfobutyl ether $\beta-C D$ had a higher binding affinity than neutral $\beta-C D$ for neutral guest species. In the case of papaverine, a protonated species, the binding constants were evaluated as 10 and 570, in the presence of the neutral $\beta-C D$ and the negatively charged $\beta-C D$, respectively. It was concluded that the charge on the cyclodextrin gave a further site of interaction for the protonated guest molecule.

In this paper we investigate the formation of an inclusion complex between sulfonated $\beta-C D$ and dopamine, a member of the catecholamine family. Catecholamines have a wide variety of biological functions ranging from hormones (adrenaline, noradrenaline), neurotransmitters (dopamine), aminoacids (tyrosine), melanin precursors (dopa) to therapeutic agents. Dopamine is also an interesting guest as it is protonated at near-neutral $\mathrm{pH}$, providing a positively charged guest molecule. There are no reports, to the best of our knowledge, on the formation of inclusion complexes between DA and an anionic $\beta$-CD. UV-visible spectroscopy and ${ }^{1} \mathrm{H}$ NMR 
measurements were used to study the complexation process and to obtain a measure of the stability of the host-guest complex, while cyclic voltammetry was used to probe the influence of the supporting solution.

\section{Experimental}

Dopamine hydrochloric salt and sulfonated $\beta$-cyclodextrin sodium salt were purchased from Sigma-Aldrich and were used as received. The degree of sulfation was reported as $7-11 \mathrm{~mol}$ of sulfonated groups per mol of $\beta$-cyclodextrin $(\beta-C D)$. All other reagents were of analytical grade and were obtained from either Sigma-Aldrich or Riedel de-Haen and were used as received. The glassy carbon (GC) (4 mm in diameter) was supplied by Goodfellow.

Spectrophotometric studies were carried out with a Cary 50 UV-visible spectrometer. The DA guest was kept at a constant concentration of $5.00 \times 10^{-4} \mathrm{~mol} \mathrm{dm}^{-3}$ in a citrate-phosphate buffer, while the concentration of the sulfonated $\beta-C D$ host was varied over the range of $5.65 \times 10^{-4}$ to $2.00 \times 10^{-2} \mathrm{~mol} \mathrm{dm}^{-3}$. The UV absorption spectrum of each sample was obtained and the data were analysed at $280 \mathrm{~nm}$ ( $\lambda_{\max }$ of DA). The citrate-phosphate buffer was formed by mixing $62.1 \mathrm{~mL}$ of $0.2 \mathrm{~mol} \mathrm{dm}^{-3} \mathrm{Na}_{2} \mathrm{HPO}_{4}$ and $37.9 \mathrm{~mL}$ of $0.1 \mathrm{~mol} \mathrm{dm}^{-3} \mathrm{C}_{6} \mathrm{H}_{8} \mathrm{O}_{7}$ to give a $\mathrm{pH}$ of 6.0. Other $\mathrm{pH}$ values were obtained by adjusting the ratio of $\mathrm{Na}_{2} \mathrm{HPO}_{4}$ to $\mathrm{C}_{6} \mathrm{H}_{8} \mathrm{O}_{7}$. In the Job's analysis, two stock solutions of $1.0 \times 10^{-4} \mathrm{~mol} \mathrm{dm}^{-3} \mathrm{DA}$ and $1.0 \times 10^{-4} \mathrm{~mol} \mathrm{dm}^{-3} \mathrm{~S} \beta-\mathrm{CD}$ were prepared and then mixed to give DA mole fractions varying from 0.0 to 1.0 in increments of 0.1. All experiments were carried out at least three times and the results presented are the average of all experiments.

${ }^{1} \mathrm{H}$-NMR experiments were performed on a Bruker $300 \mathrm{MHz}$ NMR spectrometer at $293 \mathrm{~K}$ in $\mathrm{D}_{2} \mathrm{O}$ (>99.92\% isotopic purity and purchased from Apollo Scientific). ${ }^{1} \mathrm{H}$ NMR peak protons were reported in ppm. A $0.1 \mathrm{~mol} \mathrm{dm}^{-3} \mathrm{KCl}$ was used to buffer the ionic strength, as the sulfonated $\beta-C D$ is highly charged and ionised. Varying amounts of sulfonated $\beta-C D$ dissolved in $0.1 \mathrm{~mol} \mathrm{dm}{ }^{-3} \mathrm{KCl} / \mathrm{D}_{2} \mathrm{O}$ were added to a $5.00 \times 10^{-4} \mathrm{~mol} \mathrm{dm}{ }^{-3}$ DA stock solution, made up in $0.1 \mathrm{~mol} \mathrm{dm}^{-3} \mathrm{KCl} / \mathrm{D}_{2} \mathrm{O}$, in order to generate final sulfonated $\beta$ $\mathrm{CD}$ concentrations ranging from $1.00 \times 10^{-4}$ to $2.50 \times 10^{-3}$ $\mathrm{mol} \mathrm{dm}{ }^{-3}$. The samples were allowed to equilibrate for $60 \mathrm{~min}$ before acquiring the ${ }^{1} \mathrm{H}$ NMR spectra. This is somewhat different to the method used in the literature where the ligand is added to the $\mathrm{CD}$ and variations in the proton resonances of the $\mathrm{CD}$ are followed. However, the NMR spectrum of the S $\beta-C D$ is too complex (with 711 sulfonated groups, giving different isomers with overlapping and poorly defined signals). Accordingly, the aromatic region of the DA guest molecule was monitored on varying the concentration of the $S \beta-C D$ to follow the formation of the inclusion complex.

Cyclic voltammetry was carried out using a Solartron Model SI 1285 potentiostat. All measurements were made at room temperature in a standard three-electrode cell with a glassy carbon (GC) electrode as the working electrode, saturated calomel electrode (SCE) as the reference electrode and a high surface area platinum wire as the counter electrode. The GC electrodes were encased into a larger insulating Teflon sheath and set in place using a non-conducting epoxy resin. Electrical contact was achieved using a copper wire. The cyclic voltammograms were recorded at $50 \mathrm{mV} \mathrm{s}^{-1}$ in the potential interval of $-250-800 \mathrm{mV}$ vs. SCE. The DA concentration was maintained fixed at $5.00 \times 10^{-4} \mathrm{~mol} \mathrm{dm}{ }^{-3}$ in the supporting electrolyte at a constant $\mathrm{pH}$, while the concentration of the sulfonated $\beta-C D$ host was varied over the range of $3.12 \times 10^{-4}$ to $2.00 \times 10^{-2} \mathrm{~mol} \mathrm{dm}^{-3}$. Different supporting electrolytes were used and these included $0.2 \mathrm{~mol} \mathrm{dm}^{-3} \mathrm{NaCl}, 0.2 \mathrm{~mol} \mathrm{dm}^{-3} \mathrm{KCl}$, $0.2 \mathrm{~mol} \mathrm{dm}^{-3} \mathrm{CaCl}_{2}, 0.2 \mathrm{~mol} \mathrm{dm}^{-3} \mathrm{NH}_{4} \mathrm{Cl}, 0.2 \mathrm{~mol} \mathrm{dm}^{-3} \mathrm{Na}_{2} \mathrm{SO}_{4}$, $0.2 \mathrm{~mol} \mathrm{dm}^{-3} \mathrm{Na}_{2} \mathrm{HPO}_{4}$ and $0.2 \mathrm{~mol} \mathrm{dm}^{-3} \mathrm{Na}_{2} \mathrm{H}\left(\mathrm{C}_{3} \mathrm{H}_{5} \mathrm{O}(\mathrm{COO})_{3}\right)$. All solutions were adjusted to a constant pH of 5.0. A citrate-phosphate buffer was also used.

\section{Results and discussion}

\subsection{UV spectrophotometric approach}

Dopamine absorbs in the UV region with an absorption maximum at $280 \mathrm{~nm}$, while the sulfonated $\beta$-CD has little or no absorbance at this wavelength, making it easy to follow the formation of the DA-sulfonated $\beta$-CD using a spectrophotometric approach.

The absorption spectra of DA $\left(\lambda_{\max }=280 \mathrm{~nm}\right)$ in the absence and presence of varying concentrations of sulfonated $\beta-C D$ are overlaid in Fig. 1. It can be seen that increasing the concentrations of sulfonated $\beta-C D$ gives rise to an overall decrease in band intensity at $280 \mathrm{~nm}$, or a hypochromic effect. This hypochromic effect is shown more clearly in Fig. 2, which plots the absorbance value at $280 \mathrm{~nm}$ against the concentration of the sulfonated $\beta$-CD present in the sample solution. A simultaneous bathochromic shift is evident with increasing concentrations of sulfonated $\beta-C D$. This red shift of the spectral band to longer wavelengths, or bathochromic effect, has been reported previously with other guest molecules and has been explained in terms of a change in the environment of the molecule as it is included within the cavity of the CD [2022]. However, it is important to state that this method, although normally used in most of the reported UV studies, is only correct when the effect caused by the presence of the cyclodextrin is just the increase in the absorbance of a given peak, without any wavelength shift. This is the case of the spectra reported herein. An isosbestic point at $282 \mathrm{~nm}$ is also clearly evident in Fig. 1, indicating the presence of two chemically different DA species, one free and the other complexed. As shown in Fig. 2, the absorbance becomes smaller with increasing concentrations of sulfonated $\beta-C D$, reaching a near constant value at concentrations close to $0.01 \mathrm{~mol} \mathrm{dm}^{-3}$ suggesting that the DA is completely included within the cavity when a large excess of the sulfonated $\beta-C D$ is present in solution. A similar observation was made by Yanez et al. [23] for the complexation of nicardipine with $\beta$-CD. These changes in the absorption spectrum of DA upon addition of the sulfonated $\beta-C D$ are consistent with the formation of an inclusion complex between DA and the sulfonated $\beta-C D$.

In order to obtain information on the stoichiometry of the inclusion complex, a Job's plot was generated using the UV data. The absorbance spectra of different solutions of DA and sulfonated $\beta$ $C D$, where the mole fraction of DA was varied from 0.0 to 1.0 in increments of 0.1 , were recorded. The change in the absorbance at $280 \mathrm{~nm}$ relative to that of an equal concentration of free DA

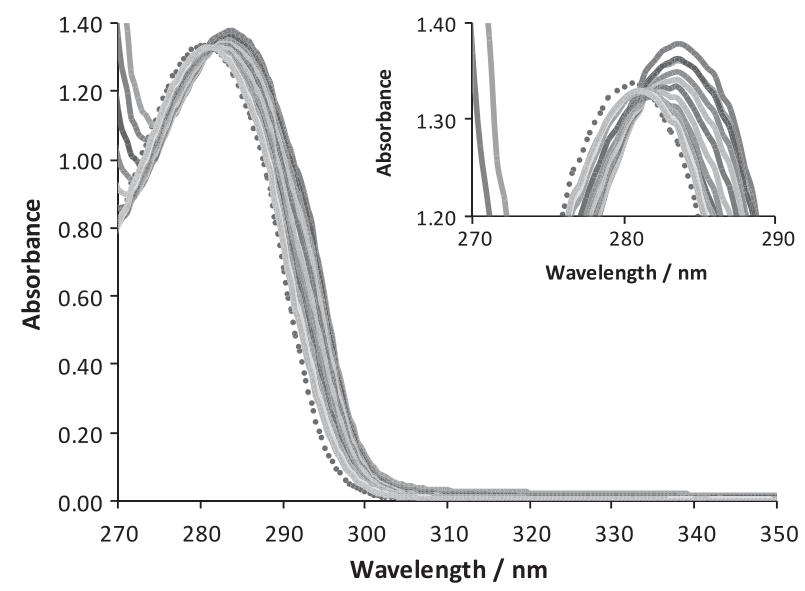

Fig. 1. UV spectra of $5.00 \times 10^{-4} \mathrm{~mol} \mathrm{dm}{ }^{-3} \mathrm{DA}$ in the absence (- - - - ) and presence of varying amounts of sulfonated $\beta$-CD from $5.65 \times 10^{-4}$ to $2.00 \times 10^{-2} \mathrm{~mol} \mathrm{dm}^{-3}$ $(--)$ in a citrate-phosphate buffer, $\mathrm{pH}=6.0$. Inset highlights the $280 \mathrm{~nm}$ wavelength of interest. 


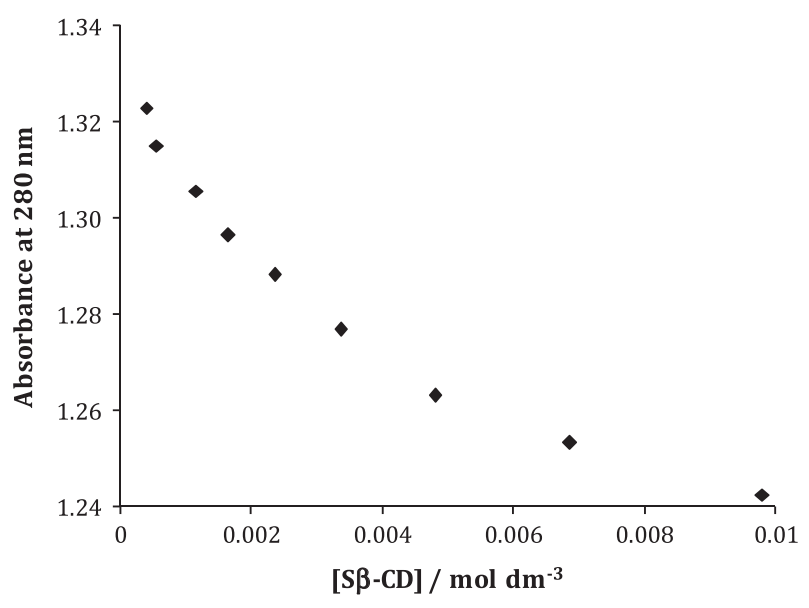

Fig. 2. Absorbance of $5.0 \times 10^{-4} \mathrm{~mol} \mathrm{dm}{ }^{-3} \mathrm{DA}$ recorded at $280 \mathrm{~nm}$ as a function of the concentration of sulfonated $\beta-\mathrm{CD}$ in a citrate-phosphate buffer, $\mathrm{pH}=6.0$.

was computed as $\Delta A=A_{\mathrm{DA}}-A_{\mathrm{DA}-\beta-\mathrm{CD}}$ and this was then used to generate the Job's plot. A typical Job's plot is presented in Fig. 3. It is clear that the maximum absorbance is obtained at a mole fraction of 0.5 , indicating a $1: 1$ stoichiometric ratio for the inclusion complex, i.e., one DA molecule included in one sulfonated $\beta$-CD host.

The association constant for the inclusion complex was evaluated using the Heildebrand-Benesi relationship provided in Eq. (1), where $A_{0}$ and $A$ are the absorbencies of the free guest and the complex, respectively, and $\varepsilon_{G}$ and $\varepsilon_{H-G}$ are the absorption, or extinction coefficients of the guest and the complex, respectively.

$\frac{A_{0}}{A-A_{0}}=\frac{\varepsilon_{G}}{\varepsilon_{H-G}-\varepsilon_{G}}+\frac{\varepsilon_{G}}{\varepsilon_{H-G}-\varepsilon_{G}} \times \frac{1}{K_{f}[\mathrm{CD}]}$

In Fig. 4, a Heildebrand-Benesi plot is presented, giving a linear relationship with a correlation coefficient of 0.997 . From the intercept and slope, a $K_{f}$ value of $336.92 \pm 24.83$ was computed, indicating a weak inclusion complex.

\subsection{NMR study}

${ }^{1} \mathrm{H}$ NMR spectroscopy is particularly useful as it gives direct and detailed information on the dynamics of the system and on the individual nuclei which are involved in forming the inclusion complex. However, in this analysis, the NMR study was used only to validate the UV-Vis measurements and to give some indications

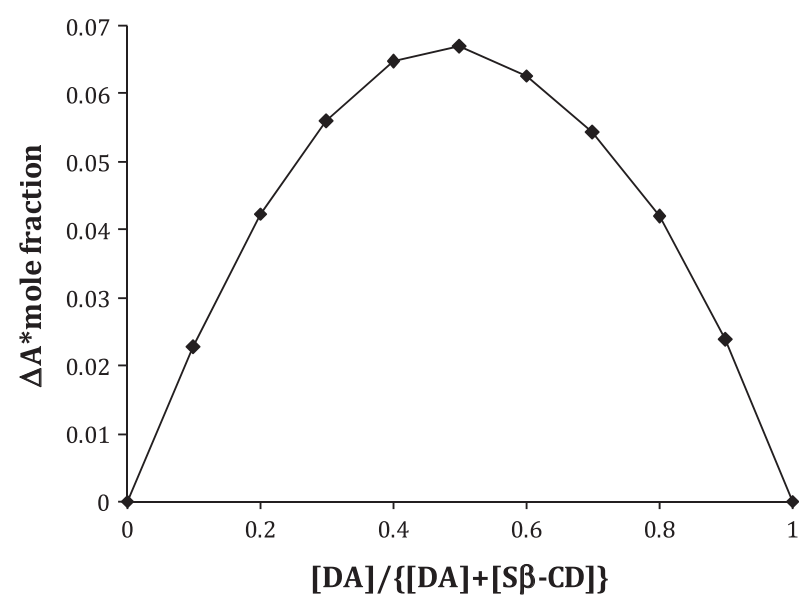

Fig. 3. Job's plot curve generated from UV data recorded for DA with various amounts of sulfonated $\beta-C D$ in a citrate-phosphate buffer, $\mathrm{pH}=6.0$.

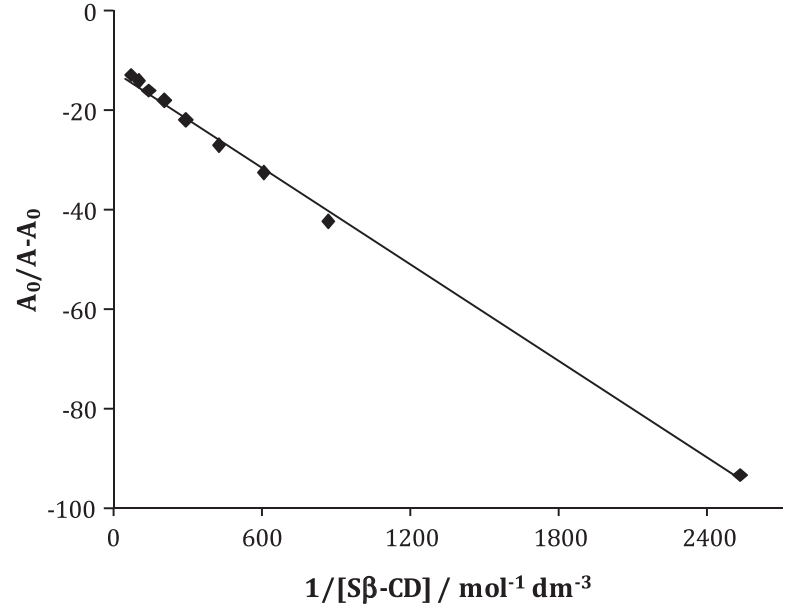

Fig. 4. Plot of $\left(A_{0} / A_{0}-A\right)$ as a function of $(1 /[S \beta-C D])$ for data recorded with $5.0 \times 10^{-4} \mathrm{~mol} \mathrm{dm}^{-3} \mathrm{DA}$ in the presence of sulfonated $\beta-C D$ in a citrate-phosphate buffer, $\mathrm{pH}=6.0$.

of a probable geometry of the inclusion complex. Due to the complex ${ }^{1} \mathrm{H}$ NMR spectrum of the $S \beta$-CD with overlapping signals, only the chemical shifts of the aromatic DA protons could be monitored. Moreover, meaningful two-dimensional correlations, such as NOESY, which involve an analysis of the protons from the $S \beta-C D$ could not be extracted.

The spectrum of the DA in a deuterated solvent was first measured, small aliquots of $S \beta-C D$ were then added and the spectrum was recorded. In all these experiments, the concentration of the DA guest was kept constant and the concentration of the sulfonated $\beta-C D$ host was varied. Fig. 5a shows the aromatic region of the ${ }^{1} \mathrm{H}$ NMR spectra of $5.0 \times 10^{-3} \mathrm{~mol} \mathrm{dm}^{-3} \mathrm{DA}$ and a mixture of $5.0 \times 10^{-3} \mathrm{DA}$ and $0.02 \mathrm{~mol} \mathrm{dm}^{-3}$ sulfonated $\beta-\mathrm{CD}$. The letters shown on the plot represent the aromatic protons depicted in Fig. 5b, and serve to illustrate the chemical shift of the individual protons in the presence of the sulfonated $\beta-C D$. It is evident from Fig. 5a that the chemical shift of the $\mathrm{a}-\mathrm{H}$ proton in DA is significant, with $\Delta \delta$ at $0.106 \mathrm{ppm}$. There is less of a chemical shift in the $\mathrm{b}-\mathrm{H}$ proton, $\Delta \delta=0.017 \mathrm{ppm}$, while the chemical shift of the $\mathrm{c}-\mathrm{H}$ is negligible, with $\Delta \delta$ at $0.002 \mathrm{ppm}$, indicating that it remains outside the CD cavity. This upfield, or low frequency shift, of the aromatic $\mathrm{a}-\mathrm{H}$ protons on the DA molecule indicates a shielding effect, which is probably due to the increase in the electron density inside the cavity from the non-bonding electron pairs of the glycosidic oxygen bridges [24]. This is clear evidence that the aromatic ring of the DA molecule penetrates the cavity of the sulfonated $\beta-C D$.

The formation, or association, constant for the inclusion complex was evaluated using the NMR data and a non-linear least square analysis using the relationships, described as follows [25].

$\delta=\delta_{h}-\frac{\Delta \delta}{2}\left(b-\sqrt{b^{2}-4 R}\right)$

where

$b=1+R+\frac{1}{(K[\mathrm{CD}])}$

Here, $\delta$ is the observed chemical shift of the protons, $\delta_{h}$ is the chemical shift observed in the presence of the sulfonated $\beta-C D$ and $R$ is the mole fraction. In Fig. 6 a plot of $\Delta \delta$ of the $\mathrm{a}-\mathrm{H}$ and $\mathrm{b}-\mathrm{H}$ protons of DA as a function of the sulfonated $\beta-C D$ molar ratio is presented. Using a non-linear curve fitting method, the $K_{f}$ value was determined as $384.5 \pm 164.8$ and $394.39 \pm 163.8$ for the $\mathrm{a}-\mathrm{H}$ and $\mathrm{b}-\mathrm{H}$ 
(a)

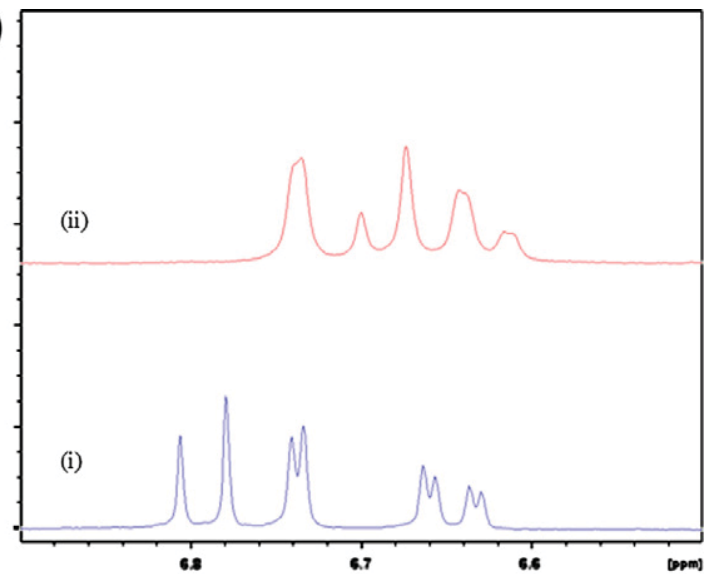

(b)

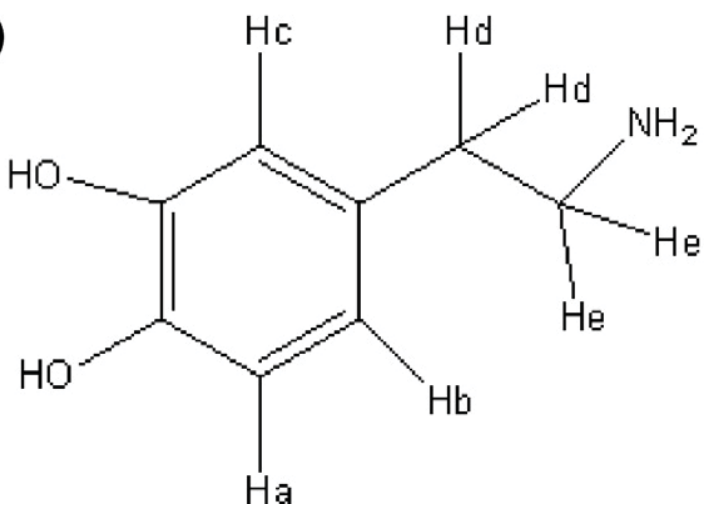

Fig. 5. (a) ${ }^{1} \mathrm{H}$ NMR spectra of the DA aromatic region in $\mathrm{D}_{2} \mathrm{O}$ and $0.1 \mathrm{~mol} \mathrm{dm}{ }^{-3} \mathrm{KC}$ for (i) $5 \times 10^{-4} \mathrm{~mol} \mathrm{dm}^{-3} \mathrm{DA}$, (ii) $5 \times 10^{-4} \mathrm{~mol} \mathrm{dm}^{-3} \mathrm{DA}$ and $0.02 \mathrm{~mol} \mathrm{dm}^{-3}$ sulfonated $\beta-C D$. (b) Labeled protons in DA molecule.

protons, respectively. This is in good agreement with the value of $336.92 \pm 24.83$ obtained with the spectrophotometric approach.

A schematic of the probable inclusion complex is presented in Fig. 7 , which shows the $\mathrm{c}-\mathrm{H}$ proton and the protonated amine group outside the cavity and the $\mathrm{a}-\mathrm{H}$ proton residing deep within the cavity. It is highly probable that the protonated amine group is bound electrostatically by the anionic sulfonated groups on the rim of the cavity. Indeed, Bratu et al. [26] observed that the methylene groups of fenbufen remained outside the cavity of neutral $\beta-C D$ and the fenbufen molecule entered from the larger side or the second-

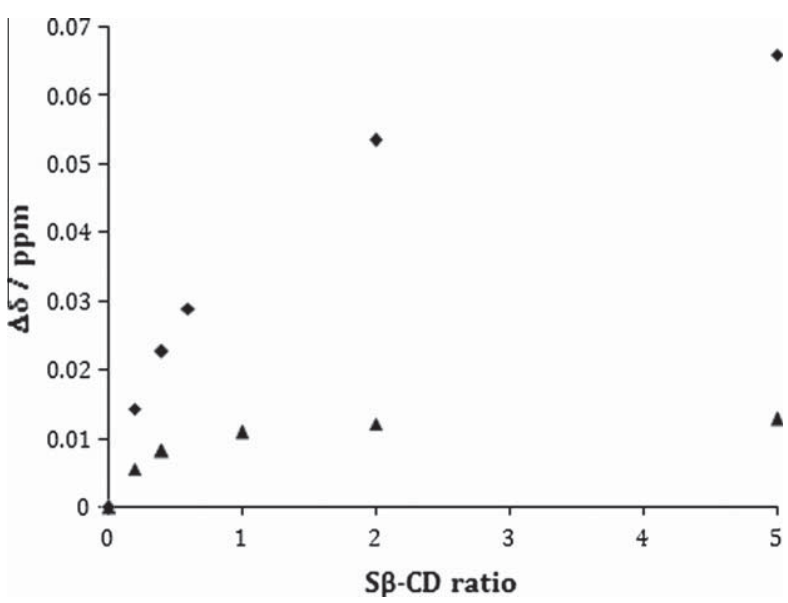

Fig. 6. Plot of chemical shift in $\mathrm{a}-\mathrm{H}(\boldsymbol{)})$ and $\mathrm{b}-\mathrm{H}(\boldsymbol{\Delta})$ protons of $\mathrm{DA}$ as a function of the mole fraction of sulfonated $\beta-C D$ in the solution.

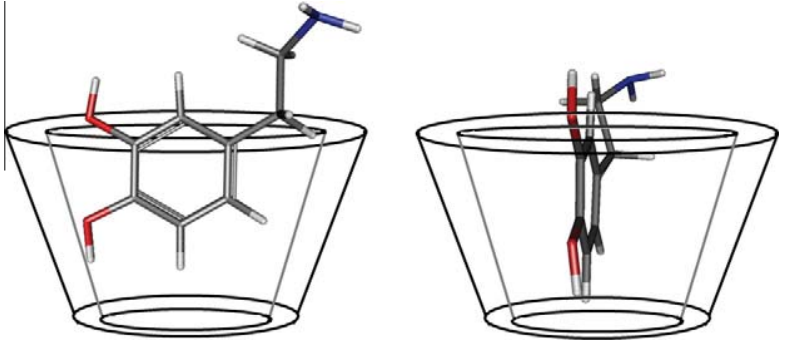

Fig. 7. A schematic representation of the inclusion complex between $D A$ and $S \beta-C D$.

ary opening of the $\beta-\mathrm{CD}$ ring. Also Chao et al. [27] demonstrated, using NMR that the aromatic ring of caffeic acid, a molecule with similarities to DA, lay inside the $\beta$-CD cavity, while the more polar groups remained outside the cavity. This schematic represents one possible arrangement, and without any detailed information on the proximity of the protons of the DA and the $S \beta-C D$, it is impossible to draw any further conclusions on the geometry of the inclusion complex.

3.3. Influence of $\mathrm{pH}$, cations and anions on formation of the inclusion complex

As the guest and host molecules are both charged species, the $\mathrm{pH}$ and composition of the supporting solution was varied to determine if this would influence the inclusion of DA within the cavity of the sulfonated $\beta$-CD. The $\mathrm{pH}$ of the citrate-phosphate buffer was adjusted from 6.0 to 3.0 and UV spectroscopy was used to follow the formation of the inclusion complex. On analysis of the data, a plot similar to that obtained in Fig. 4 was obtained, giving a $K_{f}$ value of $452.68 \pm 12.45$. This is somewhat higher than the value obtained at a $\mathrm{pH}$ of 6.0 and may be connected to the level of protonation of the DA molecule. The ratio of DA in the neutral and protonated states can be obtained by considering the Henderson Hasselbalch equation, given below in Eq. (3), where $\mathrm{HA}^{+}$represents the protonated DA and $A$ indicates the neutral form $\left(\mathrm{HA}^{+} \leftrightharpoons \mathrm{H}^{+}+\mathrm{A}\right)$.

$\mathrm{pH}=\mathrm{p} K_{\mathrm{a}}+\log \frac{[\mathrm{A}]}{\left[\mathrm{HA}^{+}\right]}$

This relationship can be arranged to give Eq. (4), providing the ratio of the neutral to the protonated $\mathrm{DA}$, in terms of the $\mathrm{pH}$ and pKa value of DA, which is 8.9.

$10^{\mathrm{pH}-\mathrm{pKa}}=\frac{[\mathrm{A}]}{\left[\mathrm{HA}^{+}\right]}$

Using this relationship, the ratio of protonated DA to the neutral DA is computed as $7 \times 10^{5}$ and $7 \times 10^{3}$ at $\mathrm{pH}$ values of 3.0 and 6.0, respectively, indicating a slightly higher proportion of neutral DA molecules at $\mathrm{pH} 6.0$ compared to $\mathrm{pH} 3.0$, which may be connected to the increase in the $K_{f}$ value as the $\mathrm{pH}$ is varied from 6.0 to 3.0. It was not possible to increase the $\mathrm{pH}$ of the DA above 8.9 to generate higher amounts of the neutral DA, as DA is oxidised under these conditions. However, when the $\mathrm{pH}$ was reduced further to 1.4 with a $0.1 \mathrm{~mol} \mathrm{dm}^{-3}$ sulfuric acid solution, a reduction in the $K_{f}$ value to $261.87 \pm 28.61$ was found. This suggests that the nature of the supporting solution has an influence on the formation of the inclusion complex with the sulfuric acid inhibiting the complexation.

Accordingly, a set of experiments was carried out to establish if the sulfate and citrate anions had any role to play in the complexation of DA with the sulfonated $\beta-C D$. In addition, the influence of cations was investigated by using chloride salts of sodium, ammonium, potassium and calcium. The ammonium cation was 
selected as the $\mathrm{NH}_{4}^{+}$can be related to the protonated DA and may compete with the electrostatic interactions between protonated $\mathrm{DA}$ and the sulfonated groups on the $\beta-\mathrm{CD}$. As DA is electroactive and easily oxidized, these studies were carried out using voltammetry. Cyclic voltammograms were recorded at a glassy carbon electrode in $5.00 \times 10^{-4} \mathrm{~mol} \mathrm{dm}^{-3} \mathrm{DA}$ in the absence and presence of $0.02 \mathrm{~mol} \mathrm{dm}^{-3}$ sulfonated $\beta-\mathrm{CD}$ in each supporting electrolyte. The $\mathrm{pH}$ was maintained constant at a $\mathrm{pH}$ of 5.0. In the case of the influence of the cations, the anion was kept constant; only chloride salts were used. Fig. 8 shows typical voltammograms for the oxidation of DA in each supporting electrolyte; $0.2 \mathrm{~mol} \mathrm{dm}^{-3}$ solutions of $\mathrm{NaCl}, \mathrm{KCl}, \mathrm{CaCl}_{2}$ and $\mathrm{NH}_{4} \mathrm{Cl}$. The data shown correspond to the 5 th cycle of the voltammogram. Oxidation of DA is observed with a peak potential, $E_{\mathrm{p}}^{\mathrm{A}}$, in the vicinity of $520 \mathrm{mV}$ vs. SCE, which corresponds to the oxidation of the protonated DA to the dopamine-quinone. Upon reversal of the potential, a cathodic peak, $E_{\mathrm{p}}^{\mathrm{C}}$, close to $200 \mathrm{mV}$ vs. SCE is observed, corresponding to the reduction of dopamine-quinone back to DA. This is consistent with the well-known quasi-reversible electrochemistry of DA.

On addition of an excess of the sulfonated $\beta-C D$, a considerable reduction in the peak oxidation current for the oxidation of DA was observed. The ratio of the peak oxidation current recorded in the absence and presence of the sulfonated $\beta-C D, i_{p(D A)}^{A} / i_{p(D A+S \beta-C D)}^{A}$, was calculated as 1.61, 1.59, 1.59 and 1.61 for the $\mathrm{NaCl}, \mathrm{KCl}, \mathrm{CaCl}_{2}$ and $\mathrm{NH}_{4} \mathrm{Cl}$ electrolytes, respectively, indicating little effect of the cations. These significant reductions in the oxidation current are consistent with the formation of the inclusion complex. As the sulfonated $\beta-C D$ is large and bulky it will give rise to a lowering in the diffusion coefficient of the included DA compared to the free
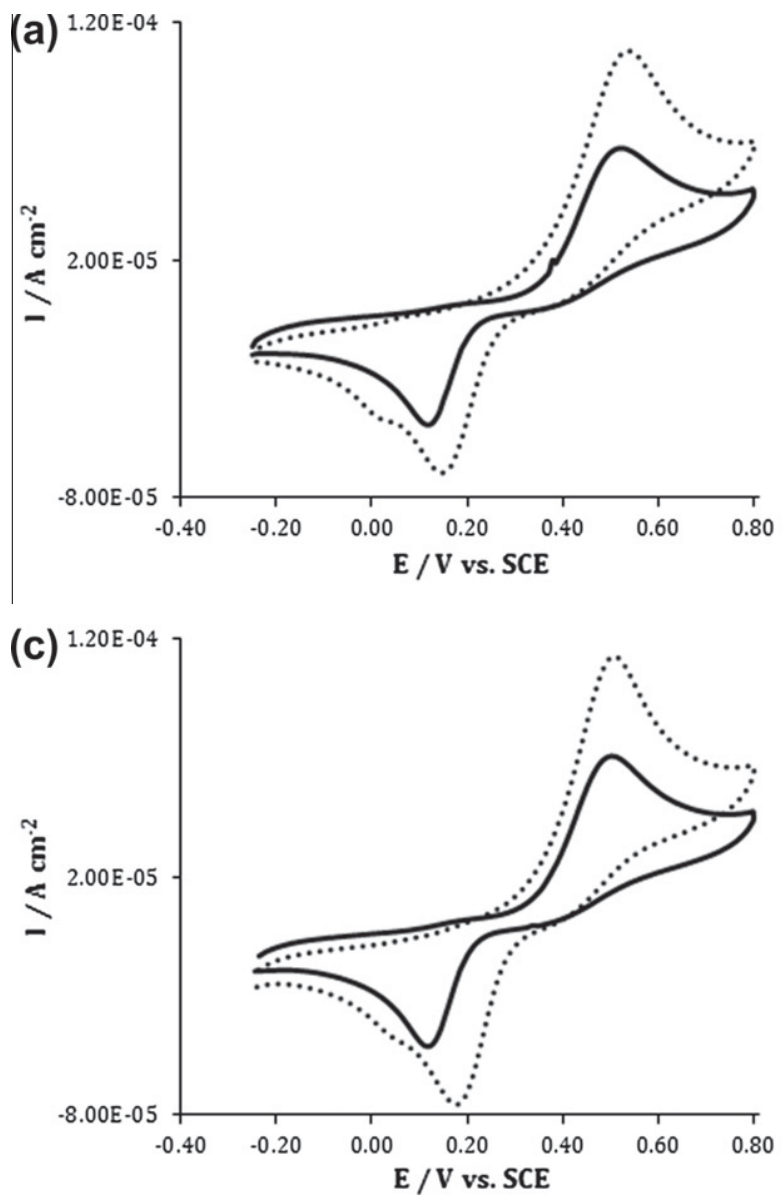

DA molecule. Indeed, this has been shown in several other works with a variety of electroactive guests and bulky cyclodextrins $[28,29]$. There is a corresponding small increase in the half-wave oxidation potential, with the greatest shift being observed in the $\mathrm{NH}_{4}^{+}$-containing electrolyte. Again, these potential shifts are indicative of an inclusion complex, where it becomes more difficult to oxidize the DA molecule confined within the sulfonated $\beta$-CD cavity. However, the different cations seem to exert little effect on the formation of the inclusion complex and there is no evidence for a competitive electrostatic interaction between the $\mathrm{NH}_{4}^{+}$and protonated DA for the anionic sulfonated groups.

On closer inspection of Fig. 8, it is clear that a shoulder peak is evident at approximately $0.0 \mathrm{mV}$ SCE in the voltammograms recorded in the absence of the sulfonated $\beta-C D$. This can be attributed to the redox reactions of the leucodopaminechrome/ dopaminochrome couple, Eq. (5), which is formed through the cyclization reaction of dopamine-quinone [30,31]. However, this reduction peak is absent in the presence of the sulfonated $\beta-C D$, which indicates that the cyclization reaction of the quinone, generated through the oxidation of DA, is inhibited when the DA is included in the cyclodextrin cavity.<smiles></smiles>

It is clear from Fig. 8, that the cations have little effect on the formation of an inclusion complex between DA and the sulfonated $\beta$-CD. Indeed, they appear to exert more influence on the
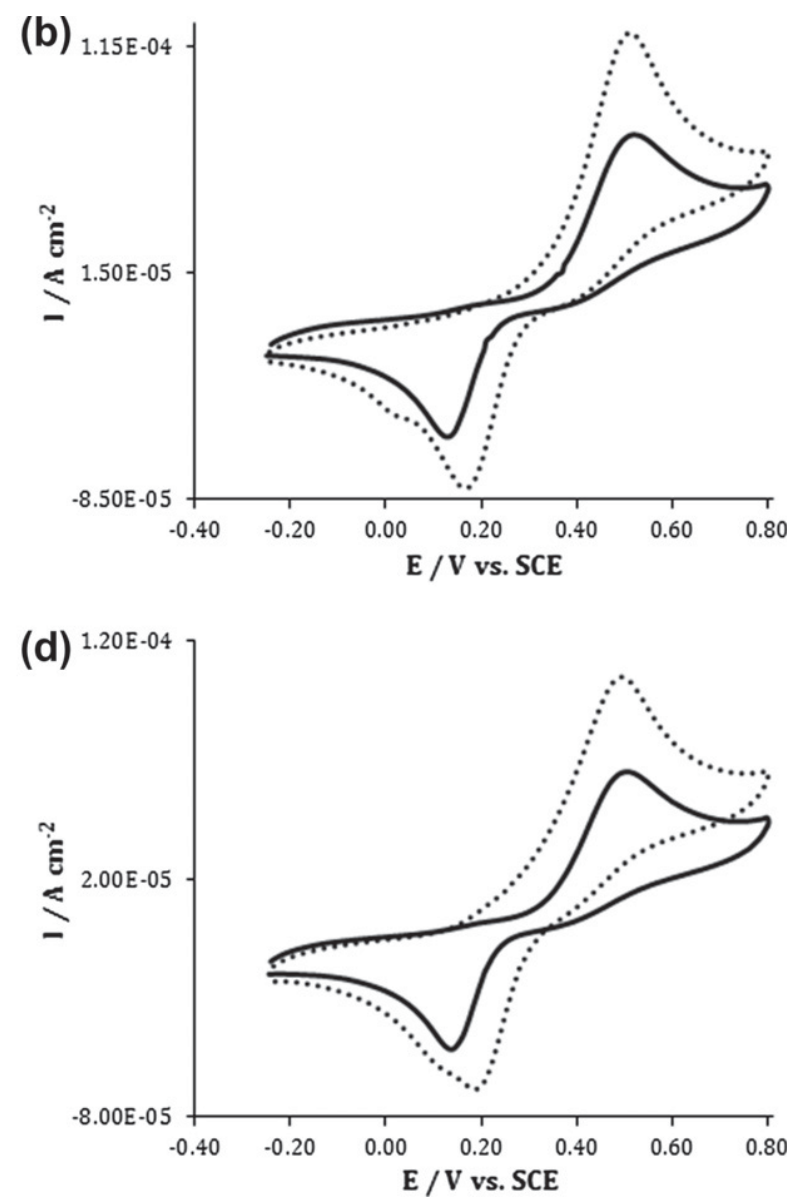

Fig. 8. Cyclic voltammograms recorded at a GC electrode at $50 \mathrm{mV} \mathrm{s}^{-1}$ in $5.0 \times 10^{-4} \mathrm{~mol} \mathrm{dm}^{-3} \mathrm{DA}$ in the absence (- - - -) and presence of $0.02 \mathrm{~mol}$ dm ${ }^{-3}$ sulfonated $\beta$-CD (--) in (a) $0.2 \mathrm{~mol} \mathrm{dm}^{-3} \mathrm{NaCl}$, (b) $0.2 \mathrm{~mol} \mathrm{dm}^{-3} \mathrm{KCl}$, (c) $0.2 \mathrm{~mol} \mathrm{dm}^{-3} \mathrm{CaCl}_{2}$ and (d) $0.2 \mathrm{~mol} \mathrm{dm}^{-3} \mathrm{NH}_{4} \mathrm{Cl}$. 


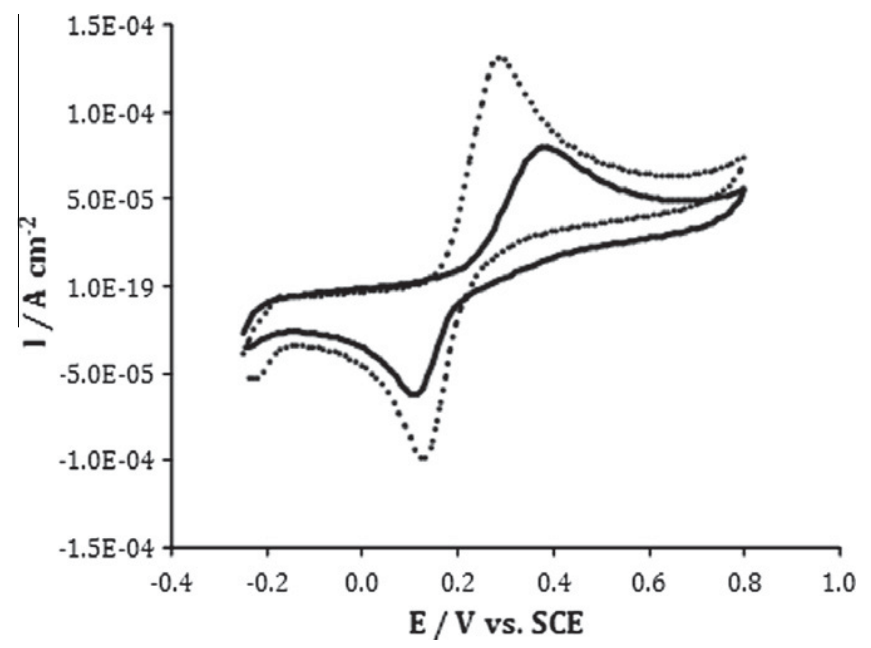

Fig. 9. Cyclic voltammograms recorded at a GC electrode at $50 \mathrm{mV} \mathrm{s}^{-1}$ in $5.0 \times 10^{-4} \mathrm{~mol} \mathrm{dm}^{-3} \mathrm{DA}$ in the absence (- - - -) and presence of $0.02 \mathrm{~mol} \mathrm{dm}^{-3}$ sulfonated $\beta-\mathrm{CD}(--)$ in citrate-phosphate buffer, $\mathrm{pH}=6.0$.

electrochemistry of the dopamine-quinone oxidation product, with a greater cathodic shift in the reduction potential of the dopaminequinone in the presence of $\mathrm{Ca}^{2+}$. On the other hand, the anion of the supporting electrolyte plays a significant role on the oxidation of DA, as shown from a comparison of Figs. 8 and 9. In Fig. 8, the voltammograms recorded in a $5.0 \times 10^{-4}$ DA solution in a citratephosphate buffer solution in the absence and presence of $0.02 \mathrm{~mol} \mathrm{dm}^{-3}$ sulfonated $\beta$-CD are compared. In this citrate-phosphate electrolyte, the $i_{\mathrm{p}(\mathrm{DA})}^{\mathrm{A}} / i_{\mathrm{p}(\mathrm{DA}+S \beta-\mathrm{CD})}^{\mathrm{A}}$ is 1.92 , while a significant shift in the half-wave potential is observed, with $\Delta E=120 \mathrm{mV}$. Similar experiments carried out in a $\mathrm{Na}_{2} \mathrm{SO}_{4}$ supporting electrolyte give an $i_{\mathrm{p}(\mathrm{DA})}^{\mathrm{A}} / i_{\mathrm{p}(\mathrm{DA}+\mathrm{S} \beta-\mathrm{CD})}^{\mathrm{A}}$ value of 1.77 and a $\Delta E$ of $85 \mathrm{mV}$. These data do indeed show that the citrate-phosphate medium facilitates formation of the inclusion complex, with the extent of complexation varying in the order $K_{f}$ (citrate-phosphate) $>K_{f}$ (sulfate) $>$ $K_{f}$ (chloride).

In an attempt to gain more information on the nature of this anion effect, voltammograms were recorded and compared for the oxidation of DA in chloride, sulfate, citrate and phosphate salts $\left(0.2 \mathrm{~mol} \mathrm{dm}^{-3}\right.$ and constant $\mathrm{pH}$ of 5.0). It was found that the electrochemical oxidation of DA was more strongly suppressed when chloride was used as a supporting electrolyte than in the case of phosphate, sulfate or citrate. The DA peak oxidation potentials, $E_{\mathrm{p}}^{\mathrm{A}}$ were found as $368 \mathrm{mV}, 411 \mathrm{mV}, 475 \mathrm{mV}$ and $524 \mathrm{mV}$ vs. SCE for the $\mathrm{Na}_{2} \mathrm{HPO}_{4}, \mathrm{Na}_{2} \mathrm{H}\left(\mathrm{C}_{3} \mathrm{H}_{5} \mathrm{O}(\mathrm{COO})_{3}\right), \mathrm{Na}_{2} \mathrm{SO}_{4}$ and $\mathrm{NaCl}$ supporting electrolytes, respectively. The $I_{\mathrm{p}}^{\mathrm{A}}$ values were determined as $13.2 \mathrm{~mA} \mathrm{~cm}^{-2}, 12.8 \mathrm{~mA} \mathrm{~cm}^{-2}, 10.7 \mathrm{~mA} \mathrm{~cm}^{-2}$ and $10.8 \mathrm{~mA} \mathrm{~cm}^{-2}$ for the $\mathrm{Na}_{2} \mathrm{HPO}_{4}, \mathrm{Na}_{2} \mathrm{H}\left(\mathrm{C}_{3} \mathrm{H}_{5} \mathrm{O}(\mathrm{COO})_{3}\right), \mathrm{Na}_{2} \mathrm{SO}_{4}$ and $\mathrm{NaCl}$ electrolytes, respectively. One possible explanation for these observations is the size and polarisability of the anions. The small chloride and sulfate anions have a stronger electrostatic binding with the protonated DA, making it more difficult to oxidise the DA molecule. The larger more diffuse anions, where the negative charge is delocalised, have a lower attraction for the protonated DA, enabling the oxidation of DA at a slightly lower potential. If this is indeed the case, then it will be more energetically favourable for the DA to remain free and uncomplexed in the sulfate and chloride media than in the citrate-phosphate medium. In contrast, the larger citrate/ phosphate species have a lower stabilisation effect on the protonated DA and it is now the formation of the complex that is more energetically favoured.

\section{Conclusions}

The question of inclusion phenomena between DA and $S \beta-C D$ was introduced and examined in this paper. It has been shown that the DA forms an inclusion complex with the CD in solution. Although, there is a difference in analysing the complexation properties of CDs in solution and on the surface, many papers have examined both these processes and have attained similar observations. This implies that we can safely say that the DA forms an inclusion complex with the $S \beta-C D$. UV spectra showed a distinct shift in the wavelength and an increase in the absorbance of the $D A$, in the presence of excess $S \beta-C D$, confirming a change in the environment of the DA and verifying complexation. The association constant, $K_{f}$, was computed as $336.92 \pm 24.83$ using UV data.

Some indication of the structure of the inclusion complex was obtained from NMR studies and concluded that the aromatic DA ring was included inside the cavity, while the protonated amine was bound through electrostatic interactions to the sulfonated groups on the rim of the $\mathrm{CD}$. It was found also that from the NMR data, using a non-linear curve fitting method, the $K_{f}$ value was determined as $384.5 \pm 164.8$ and $394.39 \pm 163.8$ for the $\mathrm{a}-\mathrm{H}$ and $\mathrm{b}-\mathrm{H}$ protons, respectively. This is in good agreement with the value obtained with the spectrophotometric approach. In all techniques the formation constants evaluated were in very close agreement, which not only validated the results, but confirmed that the methods examined for the complexation could be recommended as a reliable option in determining the formation constants of the inclusion complex of $S \beta-C D$, with other guest molecules. In comparing the data obtained in these experiments to data found in the literature for the neutral $\beta-C D, K_{f}=95.06$ [4] it can be concluded that the negatively charged sulfonate groups on the CD play an important role in the complexation and increase the binding affinities in the case of protonated DA.

In the electrochemical studies, the DA oxidation potentials shifted to higher potentials, while, the peak current decreased upon the addition of $S \beta-C D$. These traits were once more attributed to the formation of an inclusion complex due to the DA being harder to oxidise inside the cavity and the decrease in the diffusion coefficient of DA due to the less mobile bulky complex. Examinations on the influence of supporting electrolyte established that a change in the anion had an influence on the DA-S $\beta-C D$ complexation while no change was observed for the cation.

\section{Acknowledgments}

This project was supported by the Irish Research Council for Science Engineering and Technology (IRCSET) and the John and Pat Hume Scholarship at the National University of Ireland Maynooth.

\section{References}

[1] J. Szejtli, Chem. Rev. 98 (1998) 1743-1753.

[2] A.R. Hedges, Chem. Rev. 98 (1998) 2035-2044.

[3] A. Harada, Y. Takashima, H. Yamaguchi, Chem. Soc. Rev. 38 (2009) 875-882.

[4] L. Liu, Q.X. Guo, J. Incl. Phenom. Macro. 42 (2002) 1-14.

[5] R. Isnin, C. Salam, A.E. Kaifer, J. Org. Chem. 56 (1991) 35-41.

[6] N. Kandoth, S.D. Choudhury, T. Mukherjee, H. Pal, Photochem. Photobiol. 8 (2009) 82-90.

[7] L.F.B. Malta, J.D. Senra, M.E. Medeiros, O.A.C. Antunes, J. Supramol. Chem. 18 (2006) 327-331.

[8] Y. Zheng, I.S. Haworth, Z. Zuo, M.S.S. Chow, A.H.L. Chow, J. Pharm. Sci. 94 (2005) 1079-1089.

[9] Y. Liu, Y.L. Zhao, H.Y. Zhang, Z. Fan, G.D. Wen, F. Ding, J. Phys. Chem. B 108 (2004) 8836-8843.

[10] J.A. Arancibia, M.A. Boldrini, G.M. Escandar, Talanta 52 (2000) 261-268.

[11] Y.L. Loukas, E.A. Vyza, A.P. Valiraki, Analyst 120 (1995) 533-538.

[12] S.L. Ma, S. Shen, N. Haddad, W.J. Tang, J. Wang, H.W. Lee, N. Yee, C. Senanayake, N. Grinberg, J. Chromatogr. A 1216 (2009) 1232-1240. 
[13] R. Theurillat, M. Knobloch, A. Schmitz, P.G. Lassahn, M. Mevissen, W. Thormann, Electrophoresis 28 (2007) 2748-2757.

[14] N. Matthijs, Y. Vander Heyden, Biomed. Chromatogr. 20 (2006) 696-709.

[15] R.J. Tait, D.O. Thompson, V.J. Stella, J.F. Stobaugh, Anal. Chem. 66 (1994) 40134018

[16] A. Amini, T. Rundlof, M.B.G. Rydberg, T. Arvidsson, J. Sep. Sci. 27 (2004) 11021108.

[17] F.T.A. Chen, G. Shen, R.A. Evangelista, J. Chromatogr. A 924 (2001) 523-532.

[18] K. Okimoto, R.A. Rajewski, K. Uekama, J.A. Jona, V.J. Stella, Pharm. Res. 13 (1996) 256-264.

[19] V. Zia, R.A. Rajewski, V.J. Stella, Pharm. Res. 18 (2001) 667-673.

[20] C. Merino, E. Junquera, J. Jimenez-Barbero, E. Aicart, Langmuir 16 (2000) 15571565.

[21] Q.F. Zhang, Z.T. Jiang, Y.X. Guo, R. Li, Spectrochim. Acta A Mol. Biomol. Spectrosc. 69 (2008) 65-70.

[22] Y. Liu, B.H. Han, Y.T. Chen, J. Org. Chem. 65 (2000) 6227-6230.

[23] C. Yanez, L.J. Nunez-Vergara, J.A. Squella, Electroanalysis 15 (2003) 17711777.

[24] H. Dodziuk, Cyclodextrins and Their Complexes, Wiley-VCH, 2006.

[25] R.S. Macomber, J. Chem. Educ. 69 (1992) 375-378.

[26] I. Bratu, J.M. Gavira-Vallejo, A. Hernanz, M. Bogdan, G. Bora, Inclusion complex of fenbufen with beta-cyclodextrin, Biopolymers 73 (2004) 451-456.

[27] J.B. Chao, H.B. Tong, Y.F. Li, L.W. Zhang, B.T. Zhang, J. Supramol. Chem. 20 (2008) 461-466.

[28] X.J. Dang, J. Tong, H.L. Li, J. Inclusion Phenom. 24 (1996) 275-286.

[29] Z.N. Gao, X.L. Wen, H.L. Li, Study of the inclusion complexes of catecholamines with beta-cyclodextrin by cyclic voltammetry, Pol. J. Chem. 76 (2002) 10011007.

[30] U.E. Majewska, K. Chmurski, K. Biesiada, A.R. Olszyna, R. Bilewicz, Electroanalysis 18 (2006) 1463-1470.

[31] Y.F. Zhao, Y.Q. Gao, D.P. Zhan, H. Liu, Q. Zhao, Y. Kou, Y.H. Shao, M.X. Li, Q.K. Zhuang, Z.W. Zhu, Talanta 66 (2005) 51-57.

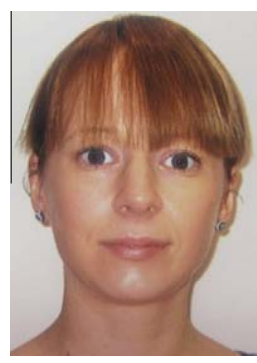

Gillian Hendy completed a single honors degree in Chemistry in 2005 and a Ph.D. in Electrochemistry in 2009 at the National University of Ireland Maynooth. She also spent 4 months at the University of Wollongong, Australia during her PhD program. She is currently undertaking an Outgoing Marie Curie Fellowship as a postdoctoral researcher at the Langer Laboratory at MIT. Her main research interests are in drug delivery and biomedical devices, drug delivery and polymers.

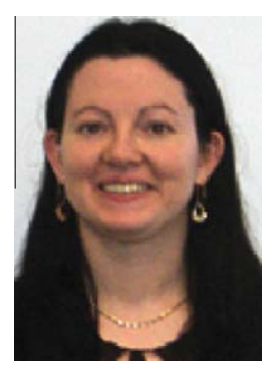

Carmel B. Breslin completed her university education at the National University of Ireland, Galway, graduating in 1987 with a degree in chemistry and again in 1990 with a Ph.D. in electrochemistry. She then joined the National University of Ireland, Maynooth where she is now professor of physical chemistry. Her research publications and interests are in electrochemistry and materials. 